УДК 342.5

DOI: 10.35750/2071-8284-2019-4-18-25.

\title{
Н.В. Варламова
}

кандидат юридических наук, доцент

Институт государства и права Российской академии наук

Российская Федерация, 119019, Москва, ул. Знаменка, д. 10

ORCID: 0000-0002-0968-3296. E-mail:varlam_n@list.ru

\section{Публичная власть: попытка концептуализации}

Аннотация: Большинство интерпретаций социальной власти базируется на её определении М. Вебером как возможности осуществления своей воли даже вопреки воле других лиц. В данном контексте власть предстаёт как способность человека и сообществ людей к принуждению других (своих членов) к определённому поведению. В первобытном обществе власть носила естественный, непосредственный, не отчуждённый ни от человека, ни от коллектива в целом характер. Её обретение и осуществление было «вплетено» в повседневную жизнедеятельность людей, а следование (коллективное подчинение) определённым правилам поведения было абсолютно необходимо для выживания и потому естественно и неоспоримо. Развитие производительной деятельности человека и его социальности в целом привело к разделению труда, в том числе и выделению властной, управленческой деятельности, и как следствие - обособлению частной и публичной сфер жизнедеятельности человека, приобретению социальной властью качества публичности. Публичная власть - это власть институционализированная; она обретается искусственными способами, выработанными социумом, и осуществляется посредством специально выделенных для этого лиц (образованных структур) в рамках установленных процедур по территориальному принципу. Публичная власть является универсальной, она распространяется на всех членов общества и на всю сферу их публичной жизнедеятельности. Возникнув в социально стратифицированном обществе, публичная власть неизбежно приобретает политический характер - она направлена на упорядочение отношений между различными группами и слоями населения, согласование (разграничение, подавление) их интересов. Именно такое понимание публичной политической власти лежит в основе различных определений государства, которые, по сути, сводятся к наиболее эффективной (суверенной), а также (в ряде концепций) надлежащей (справедливой, легитимной, правовой и т.п.) форме её организации.

Ключевые слова: власть, публичная власть, политическая власть, первобытное общество, разделение труда, легитимность, государство.

Для циитирования: Варламова Н.В. Публичная власть: попытка концептуализации // Вестник Санкт-Петербургского университета МВД России. - 2019. - № 4 (84). - С. 18-25. DOI: 10.35750/20718284-2019-4-18-25.

\author{
Natalia V. Varlamova \\ Cand. Sci. (Jurid.), Docent \\ Institute of State and Law Russian Academy of Sciences \\ 10, Znamenka str., Moscow, 119019, Russian Federation \\ ORCID: 0000-0002-0968-3296. E-mail:varlam_n@list.ru
}

\section{Public authority: attempt of conceptualization}

Annotation: The majority of interpretations of social authority is based upon its definition by M. Weber as an opportunity to exercise one's will even against the will of other persons. In this context the authority constitutes a capacity of an individual or a community of people to force others (own members) to a certain type of conduct. In the primitive society the authority was natural, direct and detached neither from an 
individual nor from a team, in general. The appropriation and exercise of authority was "interwoven" in daily activities of people and the observance (collective subordination to) of certain rules of conduct was ultimately essential for survival and thus natural and indisputable. The development of production activities of an individual and its sociality, in broad terms, led to the division of labor, inter alia, to segregation of the ruling and managerial activities and the consequent isolation of private and public areas of activity of an individual, attribution of the degree of publicity to social authority. Public authority is institutionalized authority; it is appropriated by artificial ways developed by the society and exercised through specially designated persons for these purposes (established entities) within the framework of the set procedures based on the territorial principle. Public authority is universal; it extends to all society members and to the entire area of their public activities. Once emerged in a socially stratified society, public authority inevitably acquires political nature - it is aimed at streamlining relationships between various groups and layers of the society and alignment (delineation, suppression) of their interests.

This particular comprehension of public political authority underpins various definitions of the state which basically come down to the most efficient (sovereign) as well as (in a set of conceptions) proper (fair, legitimate, legal etc.) form of its organization.

Keywords: authority, public authority, political authority, primitive society, division of labor, legitimacy, state.

For citation: Varlamova N.V. Public authority: attempt of conceptualization // Vestnik of St. Petersburg University of the Ministry of Internal Affairs of Russia. - 2019. - № 4 (84) - P. 18-25. DOI: 10.35750/20718284-2019-4-18-25.

1. Введение. Власть - инвариант любых интерпретаций государства, политической системы, социального управления. Все они так или иначе замкнуты на понятие власти, выстраиваются на основе противопоставления различных видов власти, то есть по сути сводятся к некоторой концепции властвования. При этом само исходное понятие власти часто оказывается неопределённым ${ }^{1}$, что не мешает (или кажется, что не мешает) выстраивать на его основе различные политико-правовые конструкции, исходя из обыденного (интуитивного) восприятия власти: «Мы говорим и пишем о власти в бесчисленном количестве ситуаций, и мы обычно очень хорошо знаем (или думаем, что знаем), что имеем в виду. В повседневной жизни и в научных работах мы обсуждаем местопребывание власти и её пределы, обсуждаем, у кого больше власти, как власти достичь, как её обрести, ей сопротивляться, её сохранить или укротить, как её распределить или распространить, уравновесить или максимизировать, как сделать её более эффективной и как ограничить её следствия или избежать их. И при этом среди тех, кто размыш-

${ }^{1}$ «...В науке о государстве до сей поры недостаёт ещё сколько-нибудь разработанной теории власти», - писал Н. Н. Алексеев почти столетие назад [1, с. 159]. Это замечание продолжает оставаться актуальным и сегодня. ляет на тему власти, нет согласия относительно того, как её определять, как её понимать, как её изучать и как её измерять, если это возможно. Об этом идут бесконечные споры, и конца им не видно, нет даже согласия относительно того, имеют ли смысл эти разногласия» [2, с. 92].

Есть работы, обосновывающие принципиальную непознаваемость сущности власти. Так, И.А. Исаев завершает своё историко-политологическое исследование утверждением: «С какой бы методологической или идеологической позиции мы ни подходили к проблеме Власти и Закона, очевидно одно - в них присутствует некая глубинная субстанция, проявляющаяся в разных ипостасях и в разные моменты времени, но всегда сохраняющая собственную не познанную до конца суть; эта субстанция развивается по собственным законам, отличным от законов человеческого мышления и существования. В нашу задачу входило одно - ещё раз обратить внимание на этот факт» [3, с. 253].

Существуют и вполне рациональные объяснения трудностей с формулированием понятия власти. Сам термин «власть» полисемичен и контекстуален. Очевидно, что когда говорят о родительской власти, разделении властей, власти над собой, власти красоты или денег, имеют в виду принципиально разную «власть». Но даже если определиться с контекстом (нас интересует власть в её социальном проявлении), 
проблема не становится проще. Часто «власть» по смыслу (а в некоторых языках в ряде случаев и лингвистически) оказывается неотличима от силы, мощи, могущества, господства, гегемонии, авторитета, принуждения, влияния, зависимости, контроля и т.п. и вбирает в себя все оттенки значений этих понятий. Нет единства в выборе исходного (родового) понятия для определения власти. Что такое власть: возможность или её осуществление? Атрибут, отношение или действие? [4, с. 7]. Власть может интерпретироваться в разных системах координат - категориях экономики, психологии, социологии, политики и права.

Наконец, власть является сущностно оспоримым понятием [5, p. 167-198]. Понимание власти, как и свободы, справедливости, права, демократии и т.п. политических, социологических и юридических феноменов, неизменно оказывается ценностно-зависимым; оно предопределяется ценностными ориентациями (как осознанными, так и неотрефлексированными) обосновывающих его исследователей, что предполагает бесконечные споры о содержании предлагаемого понятия [5, p. $169 ; 6$, p. 529-530] и ставит под вопрос саму возможность «объективного» определения власти $[4$, с. 11$]$.

Поэтому от понятия власти порой предлагают вообще отказаться как от «гибкого и пустого термина» [7, p. 266, 278], который лишь «приносит разочарование» и малополезен при конструировании сложных социальных систем [8, p. 70]. Однако все эти сложные социальные системы базируются именно на том или ином представлении о власти. Сущностная оспоримость понятия власти не исключает возможность (и необходимость) сопоставления разных её интерпретаций, что способствует развитию и обогащению её понимания [5, p. 168, 180-183; 6, p. 531-534].

Таким образом, полисемичность, контекстуальность и сущностная оспоримость власти не препятствуют её рациональной концептуализации, просто надо учитывать накладываемые этим ограничения.

2. Социальное измерение власти. Власть в её социальном проявлении есть средство (способ) организации (упорядочивания) социальных отношений (социального взаимодействия), совместной жизнедеятельности людей в рамках достаточно крупных социальных общностей, то есть не индивидуализированного, не собственно межличностного взаимодействия.
В таком контексте большинство исследователей ${ }^{2}$ эксплицитно или имплицитно исходят из понятия власти, предложенного М. Beбером. Он определял власть как возможность осуществить свою волю в социальном взаимодействии даже вопреки сопротивлению других лиц $[9$, p. 152; 10, p. 53, 926]. Из веберовской формулировки следует, что власть реализуется в поведении людей, в рамках определённого социального отношения. Специфика этого отношения в том, что оно асимметрично. Асимметричность отношения означает, что позиции участвующих в нём лиц различны. С одной стороны, они преследуют разные (часто противоположные, конфликтующие) интересы, а с другой - обладают разными (несопоставимыми) ресурсами (психофизическими, интеллектуальными, материальными, социальными и т.п.), необходимыми для их реализации. Собственно, это неравенство ресурсов и позволяет одному из участников отношения властвовать над другим (другими). Власть денег, красоты, авторитета и т.п. - образные выражения, в конечном счёте, указывают на отношения между людьми, в которые вовлечены и неравно распределены соответствующие ресурсы, что и предопределяет их властный характер.

Далее, власть, понимаемая как возможность реализовать свою волю, в том числе вопреки воле других людей, предполагает способность подчинить других своей воле, заставить с ней считаться, принудить к определённому поведению. Другими словами, власть - это способность к принуждению, возможность принуждать. Но «способность» И «возможность» - суть свойства, а свойство всегда валентно, то есть должно «прилагаться» к некоторому объекту или субъекту. Отсюда порой делаются выводы о некорректности такого определения власти. Исследователи проводят аналогию с понятием энергии в физике, где она определяется как «нечто, обладающее способностью совершать работу». Такое упрощение делается потому, что в физике сегодняшнего дня неизвестно, что такое энергия. Точно так же ни современной политологии, ни теории государства точно не известно, что такое власть. «Этот весьма загадочный феномен каждый исследователь испытывал на себе, многие пытались его препарировать, но он везде и нигде, и нет такого инструмента, ко-

${ }^{2}$ Обзор различных концепций власти, развиваемых в западной политологии, см., например: [4, с. 25-58]. 
торый оказался бы абсолютно пригодным для этой цели» $[11$, с. 43$]$.

Однако и из определения М. Вебера, и из социальной практики следует, что власть «прилагается» прежде всего к человеку, а затем (опосредованно) и к любой социальной общности, и к различным продуктам (в широком смысле) человеческой деятельности (власть красоты, власть музыки, власть денег и т.п.). Если в физике действительно может существовать неизвестное «нечто», способное производить работу, то в социальной жизни в конечном счёте всё сводится к человеку, поэтому и власть следует отождествлять не с некоторым непознанным объектом, а с самой способностью, свойством человека и человеческих сообществ ${ }^{3}$.

Таким образом, власть есть свойство человека, а отсюда и сообщество людей, заключающееся в способности (возможности) принуждать других (своих членов) к определённому поведению (действовать определённым образом). Отсюда власть неразрывно связана с управлением поведением людей; управление выступает как естественное проявление власти, результат и содержание её функционирования. Принуждение, способность к которому отождествляется с властью, может быть психофизическим (обусловленными естественно присущими человеку биологическими свойствами) и социальным (социально организованным).

Увязывание власти с принуждением позволяет говорить о ней как о господстве, potestas, «власти над» [2, с. 108-109]. Вообще часто встречающееся противопоставление «власти над» и «власти для» $[2$, с. 54$]$ не кажется обоснованным. Власть всегда осуществляется и «над», то есть предполагает принуждение в отношении определённого лица (группы лиц) или демонстрацию его возможности, и «для» достижения посредством принуждения определённых целей, даже если они и заключаются в самом властвовании. Обособление власти от насилия и принуждения (стремление представить её исключительно как «власть для») ограничивает и даже выхолащивает содержание понятия власти, оставляя без внимания способ, посредством которого достигаются преследуемые цели.

${ }^{3}$ Интересно, что в различных философских системах власть в пределе понимается как естественно присущее всему сущему (Природе, Космосу, отдельным их составляющим) свойство упорядочивать, а значит и способность принуждать. Другими словами, власть - не некое неизвестное (непознанное) сущее, а качество всего сущего (см., например: [3])
Так, в работах Т. Парсонса и Х. Арендт акцент делается именно на цели, реализуемые за счёт осуществления власти. По Т. Парсонсу, власть - это «генерализированная способность социальной системы» обеспечить выполнение её элементами своих обязанностей, связанных с достижением общих целей. Посредством власти реализуются коллективные цели сообщества благодаря согласию членов общества с правом определённых лиц (структур) принимать от имени сообщества решения, обязательные для его членов. Таким образом, власть у Т. Парсонса всегда социальна (принадлежит социальной системе в целом и осуществляется в её рамках), легитимна (основана на согласии подвластных) и действует в интересах общества (обеспечивая реализацию коллективных целей системы, в отношении которых достигнут консенсус). Власть не исключает применение в случае неповиновения «негативных санкций», то есть обращения к принуждению, но сама по себе возможность (угроза) принуждения без легитимации и обоснования не является осуществлением власти [12, p. 299-331; 13, p. 103].

Аналогичный и даже более привлекательный образ власти рисует Х. Арендт. Свои представления о власти она выводит из идеализированной античной концепции res publica (общего дела), трактуемой как предполагающей ненасильственное согласие и разумное поведение членов общества. Власть в её интерпретации проистекает из группы, отличающейся единством и действующей сообща. Власть всегда легитимна, существует между равными людьми, находящимися в коммуникации между собой; она отделена от господства, отношений повеления - подчинения и насилия. Власть и насилие являются антиподами. Власть не основывается на насилии; насилие не порождает, а разрушает власть [14, p. 40-52; 15, p. 59-74].

Подобное сведение власти только к её легитимным и даже консенсуальным формам оставляет без внимания её сущность - способность к принуждению, а следовательно и проблематику различения надлежащих и ненадлежащих способов организации и осуществления власти. Если легитимность действительно присуща устойчивой и интериоризованной (воспринимаемой подвластными как «своя») власти, то консенсуальность (в строгом смысле) власти противоположна, поскольку власть необходима именно как возможность обеспечить подчинение в случае несогласия (реализовать свою волю вопреки воле других лиц), что не исключает согласия с самой необходимостью существования 
власти и обращения к ней вообще и в принципе, а также с той или иной формой организации и осуществления власти.

3. Генезис публичной власти. Человек, для того чтобы удовлетворять свои естественные биологические потребности, должен существовать коллективно, в определённом взаимодействии с себе подобными. Думается, именно в этом смысле Аристотель назвал человека существом политическим [16, с. 378] (с учётом современной терминологии точнее сказать «социальным»). Изначально формы социального взаимодействия людей имели биологическое основание (по крайней мере, оно доминировало). Первобытное человеческое сообщество - это ещё не социум в собственном смысле слова, и взаимодействие внутри него - ещё не подлинно социальное взаимодействие. Первобытные коллективы скреплялись сугубо естественно, пожалуй, инстинктивно - необходимостью выживания, которое могло быть только коллективным, и кровнородственными связями. Власть и управление в таком сообществе носили естественный, непосредственный, не отчуждённый ни от человека, ни от коллектива в целом характер. Проблема персонализации власти также решалась преимущественно на биологической основе: вождями становились самые сильные, ловкие, сообразительные.

Непосредственность власти коллектива заключалась отнюдь не в том, что все его члены в равной мере участвовали в принятии решений - сама необходимость особых управленческих процедур уже элемент отчуждения - просто повседневная жизнедеятельность вынуждала каждого следовать определённым образцам поведения, коллективное подчинение им (что тождественно коллективному принуждению) было так же естественно, как совместная охота и обустройство пещеры.

Первобытное человеческое сообщество - это ещё во многом естественная популяция данного биологического вида, все формы его жизнедеятельности (в том числе власть и управление) синкретичны и биологически обусловлены. Связи между отдельными сообществами носят спорадический характер, они не являются постоянными и необходимыми. Единый человеческий социум ещё не сформировался. Территория, на которой функционирует то или иное человеческое сообщество, - это просто его естественная среда обитания.

Развитие производительной деятельности человека и его социальности в целом (доминирование социально, а не биологически обуслов- ленных форм и способов жизнедеятельности), переход от присваивающего хозяйства к производящей экономике (неолитическая революция, по Г. Чайлду [17]) и обусловленная этим возможность индивидуального присвоения произведённого продукта (частная собственность) привели к общественному разделению труда (Ф. Энгельс [18, с. 156-178]) и относительной эмансипации отдельного человека от сообщества, появлению у него своих (частных) интересов, и различию (порой доходящему до конфликта, и даже антагонизма) интересов членов общества, занимающих разное положение в системе общественного разделения труда. Все это требовало иной социальной организации. На смену естественным кровнородственным связям, скрепляющим человеческое сообщество, приходят связи социальные, прежде всего - обменные.

Вместе с разделением производительного труда (связанного с созданием и обращением товаров) происходит и выделение специфического управленческого труда (связанного с организацией производства, обмена и совместной жизнедеятельности в целом). Управление же предполагает принуждение, власть. И это уже не прежняя, естественно присущая человеку и социуму власть, а власть, которая отчуждается ими в пользу тех, кто «специализируется на управлении». Одновременно происходит обособление двух сфер жизнедеятельности человека - частной и публичной - и соответственно двух видов власти, реализуемой в них. Первая - частная, которая функционирует в семье, дружеской компании и т.п. неформальных объединениях, продолжает сохранять - пусть и в преобразованном (цивилизованном) виде - черты естественности, присущие власти в первобытных сообществах. Вторая - публичная - приобретает новые качества.

4. Признаки публичной власти. Публичная власть - власть институционализированная, то есть социально организованная и упорядоченная в качестве самостоятельной сферы человеческой деятельности. Она осуществляется специально уполномоченными на то лицами (их объединениями - институтами, органами) в рамках специальных процедур. Таким образом, публичная власть - это власть, отчуждённая от человека и от конкретного сообщества, которое как бы делегирует её отдельным лицам. Способы обретения этими лицами публичной власти могут быть самыми разными - наделение полномочиями согласно некоторой общепринятой процедуре или их присвоение, узурпация - но 
они всегда искусственны, в том смысле, что социально организованы, а не биологически обусловлены.

В силу своей отчуждённости публичная власть носит представительный характер, причём независимо от способа своего обретения. Представительность публичной власти в данном случае трактуется в более широком смысле, чем её современное понимание, основанное на идеях республиканизма, народного суверенитета и демократии. Представительный характер публичной власти предполагает, что она действует от имени и в интересах соответствующего сообщества, безусловно, в её собственном (персонифицирующих её лиц) их понимании.

В свою очередь это означает, что публичная власть нуждается в легитимации (именно утрата публичной властью естественного характера превращает её легитимацию в отдельную проблему), только тогда она будет восприниматься «представляемыми» (подвластными) в качестве «своей» власти. В противном случае имеет место не публично-властное объединение (сообщество), а частноправовое владение соответствующей территорией вместе с населением или оккупационный режим [19, с. 395-396, 409-410]. Легитимация власти как процедура объяснения и оправдания её притязаний на подчинение может базироваться на любых ценностях [20, с. 636-643] и осуществляться любым способом (если вспомнить веберовскую триаду - традиционным, харизматическим, рационально-правовым [21, с. 205-213]), но она должна быть.

Наконец, будучи «оторвана» от человека и сообщества и перенесена на специальный аппарат, публичная власть должна найти новый способ соединения с ними. Таким связующим звеном становится территория. На смену кровнородственным связям приходит связь посредством территории. Публичная власть осуществляется по территориальному принципу в отношении «публики» - всех людей, находящихся на определённом пространстве. Территория, занимаемая публично-властно организованным сообществом, - это уже не его естественная среда обитания и не собственность властвующих (или всего сообщества), а важнейший конституирующий сообщество аспект совместного социального бытия - пространственные пределы и материальная основа властвования. «Не dominium, a imperium», как подчёркивал Г. Еллинек [19, с. 387].

Возникнув в социально стратифицированном обществе, публичная власть неизбежно приобретает политический характер - она направлена на упорядочение отношений между различными группами и слоями населения, согласование (разграничение, подавление) их интересов.

Итак, публичная власть - это власть институциолизированная; она обретается искусственными способами, выработанными социумом, и осуществляется посредством специально выделенных (обособленных от остальных его членов) лиц (структур, органов) по территориальному принципу. Публичная власть носит универсальный характер, она распространяется на всех членов общества и на всю сферу их публичной жизнедеятельности.

Универсальность, политический характер и территориальный принцип осуществления отличают публичную власть от власти корпоративной, которая также является институционализированной, но неполитична, объединяет людей на персональной основе и охватывает отдельную сферу их частной (хотя и социально организованной) жизни.

5. Заключение. Виды публичной власти. Тождественна ли публичная власть государственной? Строго говоря - нет. Однако именно понятие публичной политической власти лежит в основе всех определений государства, сводимых, по сути, к любой или надлежащей (справедливой, легитимной, правовой и т.п.) форме её организации [22, с. 515-564].

Вместе с тем публичной властью является и власть муниципальная, реализуемая в рамках того или иного местного сообщества (поселения). В отличие от государственной публичной власти, муниципальная власть не является первичной [19, с. 416-419]; она производна от государственной публичной власти, функционирует в установленных ею пределах. Принято считать, что муниципальная власть не носит политического характера, она призвана разрешать вопросы местного значения (в силу чего она не является и универсальной), в отношении которых предполагается (хотя это и довольно спорно) единство интересов всех жителей, и отстаивать эти интересы перед государственной публичной властью, вовлекаясь, таким образом, в политический процесс.

Наконец, в условиях современных интеграционных процессов, обусловленных глобализацией, происходит формирование наднациональной публичной власти, реализуемой в наднациональных образованиях (к таковым прежде всего относят Европейский Союз). Будучи производной от публичной власти государствчленов, публичная власть наднационального образования относительно независима от них. Её 
решения обязательны как для самих государствчленов, так и для их граждан; они действуют непосредственно на территории государствчленов, но реализуются их органами. Наднацио- нальная публичная власть не носит универсального характера, она распространяется только на отдельные сферы сотрудничества, но постоянно стремится к их расширению [23, с. 8-34].

\section{Список литературь}

1. Алексеев Н. Н. Очерки по общей теории государства. Основные предпосылки и гипотезы государственной науки / под ред. В. А. Томпсинова. - Москва: Зерцало, 2008. - 216 с.

2. Льюкс С. Власть: Радикальный взгляд / перевод с англ. А. И. Кырлежева. - Москва: Издательский дом Государственного университета - Высшей школы экономики, 2010. - 240 с.

3. Исаев И. А. Метафизика Власти и Закона: У истоков политико-правового сознания. - Москва: Юристъ, 1998. - 256 с.

4. Ледяев В. Г. Власть: концептуальный анализ. - Москва: Российская политическая энциклопедия (РОССПЭН), 2001. - 384 с.

5. Gallie W. B. Essentially Contested Concepts // Proceedings of the Aristotelian Society. - 1956. Vol. 56. - Issue 1. - P. 167-198.

6. Waldron J. Vagueness in Law and Language: Some Philosophical Issues // California Law Review. - 1994. - Vol. 82. - No. 3. - P. 509-540.

7. Latour B. The Powers of Association / Power, Action and Belief: A New Sociology of Knowledge? / ed. by J. Law. - London; Boston: Routledge \& Kegan Paul, 1986. - P. 264-280.

8. March J. The Power of Power / Varieties of Political Theory / ed. by D. Easton. - Englewood Cliffs: Prentice-Hall, 1966. - P. 39-70.

9. Weber M. The Theory of Social and Economic Organization. - New York: Oxford University Press, 1947. $-436 \mathrm{p}$.

10. Weber M. Economy and Society / ed. by G. Roth, C. Wittich. - Berkeley; Los Angeles: California University Press, 1978. - 1462 pp.

11. Батурин Ю. М., Ливщии Р. 3. Социалистическое правовое государство: от идеи - к осуществлению (политико-правовой взгляд). - Москва: Наука, 1989. - 256 с.

12. Parsons T. Sociological Theory and Modern Society. - New York: Free Press, 1967. - 564 p.

13. Parsons T. Power and the Social System / Power / ed. by S. Lukes. - Oxford: Blackwell, 1986. P. 94-143.

14. Arendt H. On Violence. - London: Allen Lane, 1970. - 106 p.

15. Arendt H. Communicative Power / Power / ed. by S. Lukes. - Oxford: Blackwell, 1986. - P. 59-74.

16. Аристотель. Политика (1253а.9) / пер. С. А. Жебелева / Аристотель. Сочинения: в 4 т. Т. 4. - Москва: Мысль, 1983. - С. 376-644.

17. Childe G. V. Man Makes Himself. - London: Watts \& Co., 1936. - 275 p.

18. Энгельс Ф. Происхождение семьи, частной собственности и государства. В связи с исследованиями Льюиса Г. Моргана // Маркс К., Энгельс Ф. Соч. / 2-е изд. - Т. 21. - Москва: Государственное издательство политической литературы, 1961. - С. 23-178.

19. Еллинек Г. Общее учение о государстве. - Санкт-Петербург: Юридический центр Пресс, 2004. - 752 c.

20. Вебер М. Основные социологические понятия / Избранные произведения. - Москва: Прогресс, 1990. - С. 602-642.

21. Липсет С. М. Политическая социология / Американская социология. Перспективы. Проблемы, Методы. - Москва: Прогресс, 1972. - С. 203-219.

22. Четвернин В. А. Государство: сущность. Понятие, структура. Функции / Проблемы общей теории права и государства / под ред. В. С. Нерсесянца. - Москва: Издательская группа Норма Инфра-М, 1999. - С. 515-642.

23. Варламова Н. В. Проблемы институционализации наднационального уровня осуществления публично-властных полномочий // Труды Института государства и права РАН. - 2014. - № 6. - C. 8-34. 


\section{References}

1. Alekseev N. N. Ocherki po obshchei teorii gosudarstv A. Osnovnye predposylki i gipotezy gosudarstvennoi nauki / Pod red. V.A. Tompsinova. - Moskva: Zertsalo, 2008 - 216 s.

2. Lukes S. Vlast': Radikal'nyi vzglyad / Per. s angl. A.I. Kyrlezheva. - Moskva: Izdatel'skii dom Gosudarstvennogo universiteta - Vysshei shkoly ehkonomiki, 2010. - $240 \mathrm{~s}$.

3. Isaev I. A. Metafizika Vlasti i ZakonA: U istokov politiko-pravovogo soznaniya. - Moskva: Yurist», 1998. - $256 \mathrm{~s}$.

4. Ledyaev V. G. Vlast': kontseptual'nyi analiz. - Moskva: "Rossiiskaya politicheskaya ehntsiklopediYA" (ROSSPEHN), 2001. - $384 \mathrm{~s}$.

5. Gallie W. B. Essentially Contested Concepts // Proceedings of the Aristotelian Society. - 1956. - Vol. 56. - Issue 1. - P. 167-198.

6. Waldron J. Vagueness in Law and Language: Some Philosophical Issues // California Law Review. 1994. - Vol. 82. - No. 3. - P. 509-540.

7. Latour B. The Powers of Association / Power, Action and Belief: A New Sociology of Knowledge? / ed. by J. Law. - London; Boston: Routledge \& Kegan Paul, 1986. - P. 264-280.

8. March J. The Power of Power / Varieties of Political Theory / ed. by D. Easton. - Englewood Cliffs: Prentice-Hall, 1966. - P. 39-70.

9. Weber M. The Theory of Social and Economic Organization. - New York: Oxford University Press, 1947. $-436 \mathrm{p}$.

10. Weber M. Economy and Society / ed. by G. Roth, C. Wittich. - Berkeley; Los Angeles: California University Press, 1978. - 1462 pp.

11. Baturin Yu. M., Livshits R. Z. Sotsialisticheskoe pravovoe gosudarstvo: ot idei - k osushchestvleniyu (politiko-pravovoi vzglyad). - Moskva: Nauka, 1989. - $256 \mathrm{~s}$.

12. Parsons T. Sociological Theory and Modern Society. - New York: Free Press, 1967. - 564 p.

13. Parsons T. Power and the Social System / Power / ed. by S. Lukes. - Oxford: Blackwell, 1986. P. 94-143.

14. Arendt H. On Violence. - London: Allen Lane, 1970. - 106 p.

15. Arendt H. Communicative Power / Power / ed. by S. Lukes. - Oxford: Blackwell, 1986. - P. 59-74.

16. Aristotle. Politika (1253a.9) / Perevod S.A. Zhebeleva // Aristotle. Sochineniya: V 4 T. - T. 4. Moskva: Mysl', 1983. - S. 376-644.

17. Childe G. V. Man Makes Himself. - London: Watts \& Co., 1936. -275 pp.

18. Engels F. Proiskhozhdenie sem'i, chastnoi sobstvennosti i gosudarstva. V svyazi s issledovaniyami Lyuisa G. Morgana // Marx K., Engels F. Soch. / 2 izd. - T. 21. - Moskva: Gosudarstvennoe izdatel'stvo politicheskoi literatury, 1961. - S. 23-178.

19. Jellinek G. Obshchee uchenie o gosudarstve. - Sankt-Peterburg: Yuridicheskii tsentr Press, 2004. 752 s.

20. Weber M. Osnovnye sotsiologicheskie ponyatiya // Weber M. Izbrannye proizvedeniya. - Moskva: Progress, 1990. - S. 602-642.

21. Lipset S. M. Politicheskaya sotsiologiya // Amerikanskaya sotsiologiya. Perspektivy. Problemy, Metody. - Moskva: Progress, 1972. - S. 203-219.

22. Chetvernin V. A. Gosudarstvo: sushchnost. Ponyatie, struktura. Funktsii // Problemy obshchei teorii prava i gosudarstva / Pod red. V.S. Nersesyantsa. - Moskva: Izdatel'skaya gruppa NORMA - INFRA-M, 1999. - S. 515-642.

23. Varlamova N. V. Problemy institutsionalizatsii nadnatsional'nogo urovnya osushchestvleniya publichno-vlastnykh polnomochii // Trudy Instituta gosudarstva i prava RAN. - 2014. - No 6. - S. 8-34.

(с) Варламова Н. В., 2019

Статья поступила в редакцию 21.10.2019 г. 